\title{
Familial Mediterranean fever: Health-related quality of life and associated variables in a national cohort
}

Hatice Bodur ${ }^{1}$ (D), Fatma Gül Yurdakul ${ }^{1}$ (D), Mehmet Tuncay Duruöz² ${ }^{\text {ID }}$, Hasan Fatih Çay ${ }^{(D)}$,

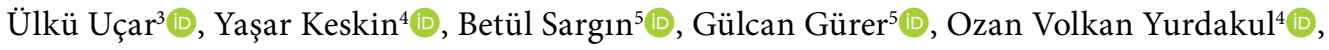
Mustafa Çalış ${ }^{6}$ (D) Hülya Deveci ${ }^{7}$, Yıldıray Aydın ${ }^{8}$ (D), Sami Hizmetli ${ }^{9}$, Remzi Çevik ${ }^{10}$ (D), Ali Yavuz Karahan ${ }^{11}$ (D), Şebnem Ataman ${ }^{12}$ (D), Hilal Ecesoy ${ }^{13}$ (D), Zafer Günendi ${ }^{14}$ (D), Murat Toprak ${ }^{15}$ (D),

Nesrin Şen ${ }^{16}(\mathbb{D})$, Duygu Altıntaş ${ }^{17}(\mathbb{D})$, Ahmet Kıvanç Cengiz ${ }^{18}$ (D), Gökhan Çağlayan ${ }^{9}$ iD, Ali Nail Demir ${ }^{19}$ (D), Hüseyin Kaplan ${ }^{6}$ (D), Sertaç Ketenci ${ }^{20}(\mathbb{D})$, Meltem Alkan Melikoğlu ${ }^{17}$ (D), Mehmet Nayimoğlu ${ }^{21}$ (D), Kemal Nas ${ }^{8}$ (D), Banu SarıfakıogluiD, İlhan Sezer ${ }^{19}$ (D)

${ }^{1}$ Department of Physical Medicine and Rehabilitation, Ankara City Hospital, Ankara, Turkey

${ }^{2}$ Department of Physical Medicine and Rehabilitation, Division of Rheumatology, Marmara University School of Medicine, Istanbul, Turkey ${ }^{3}$ Department of Physical Medicine and Rehabilitation, Division of Rheumatology, Antalya Training and Research Hospital, Antalya, Turkey

${ }^{4}$ Department of Physical Medicine and Rehabilitation, Bezmialem Vakıf University Faculty of Medicine, Istanbul, Turkey

${ }^{5}$ Department of Physical Medicine and Rehabilitation, Division of Rheumatology, Adnan Menderes University Faculty of Medicine, Aydin, Turkey

${ }^{6}$ Department of Physical Medicine and Rehabilitation, Erciyes University Faculty of Medicine, Kayseri, Turkey

${ }^{7}$ Department of Physical Medicine and Rehabilitation, Gaziosmanpaşa University Faculty of Medicine, Tokat, Turkey

${ }^{8}$ Department of Physical Medicine and Rehabilitation, Sakarya University Faculty of Medicine, Sakarya, Turkey

${ }^{9}$ Department of Physical Medicine and Rehabilitation, Division of Rheumatology, Cumhuriyet University Faculty of Medicine, Sivas, Turkey

${ }^{10}$ Department of Physical Medicine and Rehabilitation, Dicle University Faculty of Medicine, Diyarbakır, Turkey

${ }^{11}$ Department of Physical Medicine and Rehabilitation, Uşak University Faculty of Medicine, Uşak, Turkey

${ }^{12}$ Department of Physical Medicine and Rehabilitation, Division of Rheumatology, Ankara University Faculty of Medicine, Ankara, Turkey

${ }^{13}$ Department of Physical Medicine and Rehabilitation, Division of Rheumatology, Necmettin Erbakan University Faculty of Medicine, Konya, Turkey

${ }^{14}$ Department of Physical Medicine and Rehabilitation, Gazi University Faculty of Medicine, Ankara, Turkey

${ }^{15}$ Department of Physical Medicine and Rehabilitation, Van Yüzüncü Yıl University Faculty of Medicine, Van, Turkey

${ }^{16}$ Department of Physical Medicine and Rehabilitation, Division of Rheumatology, Kartal Dr. Lütfi Kirdar Training and Research Hospital, Istanbul, Turkey

${ }^{17}$ Department of Physical Medicine and Rehabilitation, Division of Rheumatology, Atatürk University Faculty of Medicine, Erzurum, Turkey

${ }^{18}$ Department of Physical Medicine and Rehabilitation, Division of Rheumatology, Sivas Numune Training and Research Hospital, Sivas, Turkey

${ }^{19}$ Department of Physical Medicine and Rehabilitation, Division of Rheumatology, Akdeniz University Faculty of Medicine, Antalya, Turkey

${ }^{20}$ Department of Physical Medicine and Rehabilitation, Division of Rheumatology, Giresun University Faculty of Medicine, Giresun, Turkey

${ }^{21}$ Department of Physical Medicine and Rehabilitation, Namık Kemal University Faculty of Medicine, Tekirdăg, Turkey

Received: May 08, 2020 Accepted: July 18, 2020 Published online: December 10, 2020

Correspondence: Fatma Gül Yurdakul, MD. Ankara Şehir Hastanesi, Fiziksel Tıp ve Rehabilitasyon Kliniği, 06800 Çankaya, Ankara, Türkiye. Tel: +90 505 - 9254214 e-mail: fatmagulonder@gmail.com

Citation:

Bodur H, Yurdakul FG, Duruöz MT, Çay HF, Uçar Ü, Keskin Y. Familial Mediterranean fever: Health-related quality of life and associated variables in a national cohort. Arch Rheumatol 2021;36(2):159-166. 


\begin{abstract}
Objectives: This study aims to evaluate the effectivity of Familial Mediterranean Fever Quality of Life (FMF-QoL) Scale for the measurement of QoL in patients with FMF and to perform correlations between related clinical variables in Turkish patients.

Patients and methods: This multicenter prospective study performed between December 2017 and November 2018 included 974 FMF patients (334 males, 640 females; median age: 35; range, 26 to 45 years). Sociodemographic characteristics and clinical features were recorded. All participants were asked to complete the FMF-QoL Scale, Short Form-36 (SF-36), Hospital Anxiety and Depression Scale (HADS), Health Assessment Questionnaire (HAQ), and Functional Assessment of Chronic Illness Therapy (FACIT) Scale.

Results: The median FMF-QoL Scale score was 26. Higher FMF-QoL Scale scores were shown to be related to female sex, illiteracy or primary education, monthly low-income (US\$<300), smoking, late-onset FMF (>20 years), a higher number of attacks per month (>1/month), and severe disease. FMF-QoL Scale scores were correlated negatively with subscales of SF-36, and positively with HADS-anxiety and HADS-depression scores, $\mathrm{HAQ}$ and FACIT.

Conclusion: Female sex, smoking, lower educational status, more severe disease, fatigue, and functional impairment were associated with poor QoL. FMF-QoL Scale was noted as a valid and simple patient-reported outcome instrument and correlated with the SF-36 scale.

Keywords: Autoinflammatory diseases, depression, fatigue, hereditary, life quality.
\end{abstract}

Familial Mediterranean fever (FMF) is a chronic debilitating and inflammatory disease affecting primarily the populations of Mediterranean origin including Non-Ashkenazi Jews, Armenians, Turks, and Arabs. ${ }^{1,2}$ It is a lifelong disease with harmful effects on all aspects of quality of life (QoL) due to the presence of recurrent attacks and side effects of medical treatment. ${ }^{3}$

The concept of health-related QoL is known as the measurement of physical symptoms, functional status, and effects of the disease on psychological and social functioning. ${ }^{2}$ As in other chronic diseases, the problems in relation to QoL for FMF patients have become an important health topic particularly during the last decades. ${ }^{1,2,4}$ It has been thought that not only QoL itself, but its measurement is also regarded as the main controversial issue for ongoing publications. ${ }^{4}$ Besides, the issue of QoL has different perspectives including pain, fatigue, mood disorders such as anxiety and depression, and sleep quality that cause difficulty in evaluating their impacts on FMF patients. ${ }^{5,6}$

Patient-reported outcome measures have been used for the assessment of QoL in patients with chronic disabling diseases. ${ }^{7}$ These measurements help physicians and health policymakers to determine psychosocial problems in patients with chronic diseases and to perform a standardized assessment of these problems. ${ }^{1,8}$ For that purpose, some scales or indices have been used including Short Form 36 (SF-36), Hospital Anxiety Depression Scale (HADS), the World Health Organization Quality of Life Scale Short Form
(WHOQOL-BREF), the Health Assessment Questionnaire (HAQ), and the Functional Assessment of Chronic Illness Therapy (FACIT)-Fatigue Scale for the measurement of QoL in rheumatological diseases and FMF patients. . $^{1,5-11}$ In addition, Familial Mediterranean Fever Quality of Life (FMF-QoL) Scale as a new, valid, and reliable scale has been also proposed. ${ }^{12}$ However, there is no consensus on the use and application of these scales or indices due to difficulties such as lack of quantitative measures and application in a busy clinical setting..$^{10}$ In this study, we aimed to evaluate the effectivity of FMF-QoL Scale for the measurement of QoL in patients with FMF and to perform correlations between related clinical variables in Turkish patients.

\section{PATIENTS AND METHODS}

This was a multicenter prospective study performed between December 2017 and November 2018, including 31 researchers as 17 rheumatologists and 14 physiatrists from 21 centers. The study protocol was approved by the Ankara Numune Training and Research Hospital Ethics Committee (approval date/no: 22.11.2107/E-17-1626). A written informed consent was obtained from each patient. The study was conducted in accordance with the principles of the Declaration of Helsinki.

All FMF patients who were older than 18 years and admitted to the rheumatology outpatient clinics of the attending centers were evaluated for the study. The diagnosis of FMF was based on the Tel Hashomer criteria, revised by Livneh. ${ }^{13}$ 
Presence of $\geq 1$ major criterion, or $\geq 2$ minor criteria, or one minor criterion plus $\geq 5$ supportive criteria, or one minor criterion plus $\geq 4$ of the first five supportive criteria was regarded as required for the diagnosis of FMF.

Patients with lack of clinical data, a new acute FMF attack within the last seven days, pregnancy, known psychological and neurological disorders, sleep disorders, chronic fatigue syndrome, chronic pain syndrome, and fibromyalgia were excluded. Therefore, a total of 974 FMF patients (334 males, 640 females; median age: 35 ; range, 26 to 45 years) were included. Of all patients, 236 (24.2\%) were between the ages of $\geq 18$ and $\leq 25$ years. Female to male ratio was 1.9 .

Sociodemographic characteristics of the patients including age, sex, educational status (illiteracy or primary education, secondary education, university or higher education), monthly income (US $\$<150$, US $\$ 150$ to 300 , US $\$ 301$ to 450 and US\$>450), the status of employment, habits of smoking and alcohol, history of FMF in the first degree relatives, and disease-related variables including duration of FMF, age of onset (grouped as $<5$ years, five to 10 years, 11 to 20 years and $>20$ years), number of attacks per month (grouped as $>2$, one to two and $<1$ ), disease severity score developed by Pras et al., ${ }^{14}$ (range, 2 to 19 points) and grading as mild ( $\leq 5$ points), moderate (6 to 10 points) and severe $(\geq 10$ points), use of colchicine, and visual analog scale patient global assessments (PGA-VAS) were recorded using online data entry. The number and percentage of the patients aged between $\geq 18$ and $\leq 25$ years were also noted. All participants were asked to complete the FMF-QoL, SF-36, HADS, HAQ, and FACIT scales. The patients who filled the FMF-QoL Scale were included in the study.

The FMF-QoL Scale includes 20 questions to assess the health status of the patients in relation to physical impact, social and recreational impact, psychological impact, and sleep impact factors. Total score changes between 0 and 80 points. Higher scores were regarded as indicators for poor QoL. ${ }^{12}$

There were 36 items with eight subscales on the SF-36. The first four subscales were used to assess the physical QoL as physical functioning, role limitations-physical, bodily pain, and general health perception. ${ }^{1}$ Mental QoL as role limitations due to emotional problems, vitality, mental health, and social functioning were assessed by the second four subscales. For each subscale, a score ranging from 0 as the worst to 100 as the best was calculated. The Turkish validation of SF-36 that has been performed previously was used for the study. ${ }^{15}$ The scores of physical component summary and mental component summary were calculated using the scores of the subscales.

By using the two subscales of HADS, both anxiety and depression subscale scores were calculated from 0 (best) to 21 (worst). There were 14 questions with Likert-type answers of four responses graded from 0 to 3 . A total HADS score was 42, and higher scores represented higher levels of anxiety and depression. For diagnoses of anxiety and depression, a score of 8 or more was regarded as the cut-off level. ${ }^{6,8,16}$ A Turkish validated form of HADS was used in the study. ${ }^{17}$

In HAQ, eight different categories with 20 specific functions were used. ${ }^{18}$ In each category, a single score equal to the maximum value of their corresponding component activities as a four point Likert scale is assigned (from 0 to 3 ). Increasing HAQ scores indicate worse functioning.

In FACIT, a self-administered instrument, the total range for scores was 0 to 52 indicating the worst possible fatigue as 0 and no fatigue as $52 .^{11}$

\section{Statistical analysis}

Evaluation of demographic and clinical features on the FMF-QoL Scale score was regarded as the main outcome. The secondary outcome was the correlation between FMF-QoL Scale and other scales.

All data were analyzed in Jamovi version 1.0.6.0 software (https://www.jamovi.org Sydney, Australia). Descriptive parameters were shown as mean \pm standard deviation, median with interquartile ranges between the $25^{\text {th }}(\mathrm{Q} 1)$ and $75^{\text {th }}$ percentiles $(\mathrm{Q} 3)$ as (Q1-Q3) or in frequencies with percentages. The numerical variables were investigated using the 
Table 1. FMF-QoL Scale values of study group based on demographic and clinical features

\begin{tabular}{|c|c|c|c|c|c|}
\hline \multirow[b]{2}{*}{ Variable } & \multicolumn{4}{|c|}{ FMF-QoL } & \multirow[b]{2}{*}{$p$} \\
\hline & $\mathrm{n}$ & $\%$ & Median & Q1-Q3 & \\
\hline Age (year) & & & 35 & $26-45$ & \\
\hline Duration of FMF (year) & & & 7 & $4-12$ & \\
\hline Disease severity score & & & 6 & $4-8$ & \\
\hline PGA-VAS & & & 7 & $5-8$ & \\
\hline $\begin{array}{l}\text { Sex } \\
\quad \text { Female } \\
\text { Male }\end{array}$ & $\begin{array}{l}640 \\
334\end{array}$ & $\begin{array}{l}65.7 \\
34.3\end{array}$ & $\begin{array}{l}28 \\
20\end{array}$ & $\begin{array}{c}15-40 \\
9-34\end{array}$ & $<0.001$ \\
\hline $\begin{array}{l}\text { Educational status } \\
\text { Illiterate or primary } \\
\text { Secondary } \\
\text { University or higher }\end{array}$ & $\begin{array}{l}289 \\
515 \\
170\end{array}$ & $\begin{array}{l}29.7 \\
52.9 \\
17.5\end{array}$ & $\begin{array}{l}32 \\
24 \\
20\end{array}$ & $\begin{array}{l}17-45 \\
12-36 \\
8-36\end{array}$ & $<0.001$ \\
\hline $\begin{array}{l}\text { Monthly income } \\
\text { US\$ }<150 \\
\text { US\$ } 150-300 \\
\text { US\$ } 301-450 \\
\text { US\$ }>450\end{array}$ & $\begin{array}{l}127 \\
239 \\
251 \\
228\end{array}$ & $\begin{array}{c}15 \\
28.3 \\
29.8 \\
27\end{array}$ & $\begin{array}{l}33.0 \\
29.0 \\
23.0 \\
19.0\end{array}$ & $\begin{array}{l}19.5-44.0 \\
15.3-42.0 \\
12.5-37.0 \\
8.0-33.0\end{array}$ & $<0.001$ \\
\hline $\begin{array}{l}\text { Status of employment } \\
\text { Employed } \\
\text { Unemployed }\end{array}$ & $\begin{array}{l}610 \\
348\end{array}$ & $\begin{array}{l}63.7 \\
36.3\end{array}$ & $\begin{array}{c}26.5 \\
24\end{array}$ & $\begin{array}{c}12-39 \\
12.8-36\end{array}$ & 0.086 \\
\hline $\begin{array}{l}\text { Smoking } \\
\text { Yes } \\
\text { Ex-smoker } \\
\text { No }\end{array}$ & $\begin{array}{l}243 \\
111 \\
620\end{array}$ & $\begin{array}{l}24.9 \\
11.4 \\
63.7\end{array}$ & $\begin{array}{l}28 \\
27 \\
25\end{array}$ & $\begin{array}{l}13-40 \\
11-37 \\
12-37\end{array}$ & 0.029 \\
\hline $\begin{array}{l}\text { Alcohol } \\
\text { Yes } \\
\text { Ex-alcohol } \\
\text { No }\end{array}$ & $\begin{array}{c}92 \\
21 \\
846\end{array}$ & $\begin{array}{c}9.6 \\
2.2 \\
88.2\end{array}$ & $\begin{array}{l}24 \\
27 \\
26\end{array}$ & $\begin{array}{l}11-36 \\
18-39 \\
12-39\end{array}$ & 0.096 \\
\hline $\begin{array}{l}\text { History of FMF in the first degree relatives } \\
\text { Yes } \\
\text { No }\end{array}$ & $\begin{array}{l}544 \\
430\end{array}$ & $\begin{array}{l}55.9 \\
44.1\end{array}$ & $\begin{array}{l}26 \\
25\end{array}$ & $\begin{array}{l}11-38 \\
13-39\end{array}$ & 0.711 \\
\hline $\begin{array}{l}\text { Age of onset (years) } \\
\quad<5 \\
5-10 \\
11-20 \\
>20\end{array}$ & $\begin{array}{l}59 \\
210 \\
312 \\
395\end{array}$ & $\begin{array}{c}6 \\
21.5 \\
32 \\
40.5\end{array}$ & $\begin{array}{l}18 \\
23 \\
25 \\
28\end{array}$ & $\begin{array}{c}9-32 \\
10-36 \\
11.8-38 \\
16-41\end{array}$ & $<0.001$ \\
\hline $\begin{array}{l}\text { Number of attacks per month } \\
\quad<1 \\
1-2 \\
>2\end{array}$ & $\begin{array}{l}443 \\
334 \\
199\end{array}$ & $\begin{array}{l}45.4 \\
34.2 \\
20.4\end{array}$ & $\begin{array}{l}22 \\
28 \\
29\end{array}$ & $\begin{array}{l}11-35 \\
14-39 \\
13-44\end{array}$ & $<0.001$ \\
\hline $\begin{array}{l}\text { Disease severity } \\
\quad \text { Mild ( } \leq 5 \text { points) } \\
\text { Moderate (6-10 points) } \\
\text { Severe ( } \geq 10 \text { points) }\end{array}$ & $\begin{array}{c}444 \\
476 \\
56\end{array}$ & $\begin{array}{c}45.5 \\
48.8 \\
5.7\end{array}$ & $\begin{array}{l}24 \\
26 \\
34\end{array}$ & $\begin{array}{l}11-36.3 \\
12-39.5 \\
20-48.5\end{array}$ & $<0.001$ \\
\hline $\begin{array}{l}\text { Use of colchicine } \\
\text { Yes } \\
\text { No }\end{array}$ & $\begin{array}{c}75 \\
899\end{array}$ & $\begin{array}{c}7.7 \\
92.3\end{array}$ & $\begin{array}{l}17 \\
26\end{array}$ & $\begin{array}{c}5.5-34 \\
13-34\end{array}$ & 0.002 \\
\hline
\end{tabular}

Shapiro-Wilk test to determine whether they were normally distributed. Groups were compared by Chi-square test, Mann-Whitney U test, and Kruskal-Wallis test. Post-hoc tests were performed using Dwass-Steel-Critchlow-Fligner pairwise comparisons. Correlations were tested by Spearman's rank correlation coefficient test. All tests were two-tailed, and an alpha significance level less than 0.05 was considered as statistically significant. 


\begin{tabular}{|c|c|c|}
\hline Variable & Median & (Q1-Q3) \\
\hline FMF-QoL & 26 & $12-38$ \\
\hline $\begin{array}{l}\text { SF-36 physical } \\
\text { Physical functioning } \\
\text { Role limitations-physical } \\
\text { Bodily pain } \\
\text { General health perception }\end{array}$ & $\begin{array}{l}57.5 \\
75.0 \\
50.0 \\
65.0 \\
45.0\end{array}$ & $\begin{array}{c}37.6-77.5 \\
55-90 \\
0-100 \\
45-77.5 \\
30-60\end{array}$ \\
\hline $\begin{array}{l}\text { SF-36 mental } \\
\text { Role limitations due to } \\
\text { emotional problems } \\
\text { Vitality } \\
\text { Mental health } \\
\text { Social functioning }\end{array}$ & $\begin{array}{l}54.6 \\
\\
67.0 \\
35.0 \\
56.0 \\
62.5\end{array}$ & $\begin{array}{c}34.3-72 \\
\\
0-100 \\
20-50 \\
44-72 \\
50-87.5\end{array}$ \\
\hline $\begin{array}{l}\text { HADS } \\
\text { Total } \\
\text { HADS-A } \\
\text { HADS-D }\end{array}$ & $\begin{array}{c}15 \\
8 \\
7\end{array}$ & $\begin{array}{l}9-20 \\
5-11 \\
3-10\end{array}$ \\
\hline HAQ & 0.17 & $0-0.83$ \\
\hline FACIT & 22 & $12-30$ \\
\hline \multicolumn{3}{|c|}{$\begin{array}{l}\text { FMF-QoL: Familial Mediterranean Fever Quality of Life Scale; SF-36: } \\
\text { Short form-36; HADS: Hospital Anxiety Depression Scale; HADS-A: } \\
\text { Hospital Anxiety Depression Scale-anxiety; HADS-D: Hospital Anxiety } \\
\text { Depression Scale-depression; HAQ: Health Assessment Questionnaire; } \\
\text { FACIT: Functional Assessment of Chronic Illness Therapy-fatigue. }\end{array}$} \\
\hline
\end{tabular}

\section{RESULTS}

The demographic and clinical features of the study group are given in Table 1 . Considering the grading of the disease, most of the patients were in the mild and moderate groups $(45.5 \%$ and $48.8 \%$, respectively).

The median FMF-QoL Scale score was 26 (Q1-Q3, range, 12 to 38). There were positive correlations between age and PGA-VAS to the FMF-QoL Scale score (Spearman's correlation coefficient 0.249 and 0.181 , respectively, $p<0.001$ for both). Higher FMF-QoL Scale scores were shown to be related with female sex, illiteracy or primary education, monthly low-income (US\$<300), smoking, late-onset FMF (>20 years), higher number of attacks per month ( $>1 /$ month), and severe disease (Table 1).

Female patients had significantly higher FMF-QoL Scale scores as 28 compared with male patients as $20(p<0.001)$.

Patients with university or higher educational status had lower FMF-QoL Scale scores (20 [Q1-Q3, 8-36]) than patients in other subgroups. The median FMF-QoL Scale score in illiterate patients or those with primary education was 29 that is significantly higher than patients with secondary education $(p<0.001)$ and those with university or higher education $(p<0.001)$.

There was a negative relationship between monthly income and FMF-QoL Scale scores. Patients with the highest monthly income (US\$ $>450$ ) had the lowest FMF-QoL Scale scores. Subgroup analysis showed that there were significant differences between monthly income of US $\$<150$ and US $\$ 301$ to $450 \quad(p<0.001)$, US $\$<150$ and US $\$>450(\mathrm{p}<0.001)$, US $\$ 150$ to 300 and US $\$>450(\mathrm{p}<0.001)$, and US $\$ 301$ to 450 and US $\$>450(p=0.027)$.

Late-onset disease ( $>20$ years) led to higher scores compared with other subgroups (Table 1). There were significant differences between patients with late-onset disease ( $>20$ years) and those with five to 10 years $(p=0.010)$ and $<5$ years $(p=0.009)$.

More than one attack per month was significantly associated with higher FMF-QoL Scale scores (Table 1). Patients with one to two attacks $(p=0.003)$ or $>2$ attacks $(p<0.001)$ had significantly higher scores than patients with $<1$ attack.

In patients with severe disease, FMF-QoL Scale score was calculated as 34

Table 3. Correlation of FMF-QoL with other scales

\begin{tabular}{lcccccc}
\hline & SF-36 physical & SF-36 mental & HADS-A & HADS-D & HAQ & FACIT \\
\hline FMF-QoL & & & & & & \\
Spearman's correlation coefficient & -0.697 & -0.644 & 0.530 & 0.626 & 0.521 & 0.715 \\
$p$ & $<0.001$ & $<0.001$ & $<0.001$ & $<0.001$ & $<0.001$ & $<0.001$
\end{tabular}

SF-36: Short Form 36; HADS-A: Hospital Anxiety Depression Scale-anxiety; HADS-D: Hospital Anxiety Depression Scale-depression; HAQ: Health Assessment Questionnaire; FACIT: Functional Assessment of Chronic Illness Therapy-fatigue; FMF-QoL: Familial Mediterranean Fever Quality of Life Scale. 
(Q1-Q3, range, 20 to 48.5). Severe disease was significantly associated with higher FMF-QoL Scale scores compared with mild disease $(p<0.001)$ and moderate disease $(p=0.015)$.

The results of patient-reported outcomes and their ranges are given in Table 2.

The FMF-QoL Scale scores were correlated negatively with subscales of SF-36, and positively with HADS-anxiety (HADS-A) and HADS-depression (HADS-D) scores, HAQ and FACIT (Table 3) ( $p<0.001$ for all).

There were 521 (53.5\%) and 420 (43.1\%) patients with anxiety and depression based on the HADS-A and HADS-D scores ( $\geq 8$ for both), respectively. There were also significant differences between FMF-QoL Scale scores in patients with anxiety (HADS-A $\geq 8$ ) (36 [Q1-Q3, 25-46.8] vs 19 [Q1-Q3, 7-30] [p<0.001]) and depression (HADS-D $\geq 8$ ) (39 [Q1-Q3, 28-49] vs 19.0 [Q1-Q3, 7-30] $[p<0.001])$.

\section{DISCUSSION}

In this study, we investigated the effectivity of FMF-QoL Scale as a new patient-reported measure in patients with FMF and showed that FMF-QoL Scale is a valid and reasonable tool to evaluate the QoL changes in these patients. In addition, we also investigated the most significant variables among the sociodemographic and clinical features affecting the QoL.

The concept of QoL in chronic diseases, specifically in FMF, has been studied for decades by several authors. ${ }^{1}$ Buskila et al. ${ }^{19}$ has been the first author to investigate this issue in patients with FMF. In this study, the authors have shown that QoL measured by the QoL scale was found to be impaired. Considering all studies on this matter, we can conclude that the QoL in patients with FMF is worse than that of healthy subjects., ${ }^{1,2}$ However, the selection of the scale to be used remains to be controversial.

Although there have been different scales to evaluate the QoL in rheumatic diseases, each of them has also been questioned as to being inadequate in assessing the subcomponents of QoL or activity of FMF. It is known that no QoL scale specific to FMF except FMF-QoL Scale exists in the literature. ${ }^{12}$ Interestingly, the use of a native-language version of any scale may be an important factor to reach reliable and feasible results. ${ }^{9}$ Although there are some Turkish validated and adapted versions of these scales (i.e. SF-36, WHOQOL-BREF, and Pediatric Quality of Life Inventory version 4.0), development of a scale by native Turkish researchers such as FMF-QoL Scale and application of this scale to Turkish FMF patients can be an important step to reach more reliable results. ${ }^{1,2,9,20}$

The controversy between similar QoL studies may have originated due to the differences in the QoL scales and sample sizes, demographic characteristics of the patients and healthy controls, and clinical features in previous studies. In recently performed studies dealing with the QoL in chronic diseases, anxiety and depression have also been investigated. ${ }^{3,5,6,8}$ Fatigue as a common and disabling syndrome that is seen in many chronic diseases has also been studied in FMF patients. ${ }^{6}$ Therefore, factors affecting the QoL in FMF patients still remain to be determined from the first study performed for this purpose. ${ }^{19}$ We used the FMF-QoL Scale in FMF patients to find the most significant variables that have a negative impact on the QoL in patients with FMF.

The association of sociodemographic and clinical features to the scores of these scales has varied in earlier studies. Considering WHOQOL-BREF, there was no correlation between the score and severity of the disease. ${ }^{9}$ This weak correlation has also been questioned previously by some researchers. ${ }^{21,22}$ Sahin et al. ${ }^{1}$ has shown the negative impact of FMF on QoL using SF-36 both in physical and mental dimensions. However, the authors did not find any significant relationship between QoL and the number of attacks and disease severity. They claimed that this may be due to the reduced sample sizes in the groups. Besides, significant improvements in SF-36 sub-components have been reported after anti-interleukin- 1 treatment. ${ }^{23}$ In pediatric and adolescent patients with FMF, the Pediatric Quality of Life Inventory has been studied with different aspects of QoL including core physical, emotional, and social health dimensions, as well as school functioning. ${ }^{2,20}$ In Alayli's study, ${ }^{2}$ there was no correlation between disease severity and QoL. Although similar 
median scores of depression and QoL were found between children and adolescents diagnosed with FMF and healthy controls, Sönmez et al. ${ }^{20}$ reported that patients with FMF had higher anxiety and depression scores in association with severity and longer duration of the disease. Thus, others and we thought that a close collaboration between pediatric psychiatrists and rheumatologists is essential for the evaluation of QoL problems in pediatric patients. ${ }^{20}$ In Giese's study, ${ }^{9}$ in which FMF patients with the same ethnicity (Turkish) living in two different countries (Turkey and Germany) were studied, there was no significant correlation between the QoL measured by WHOQOL-BREF and FMF disease activity. The authors have attempted to explain this unexpected situation. They mentioned that WHOQOL-BREF may not be a sensitive tool for disease activity due to its generic score measuring feature for QoL. In addition, they believed that the Pras score may not focus on different aspects of FMF that have a negative or positive impact on the QoL. ${ }^{9}$ Due to the fact that there should be a poorer QoL in patients with higher attacks and/or severe disease, such results should be considered with caution. In the present study, there were significant correlations between FMF-QoL Scale score and female sex, illiteracy or primary education, monthly low-income (US $\$<300)$, smoking, late-onset FMF ( $>20$ years), higher number of attacks per month $(>1 /$ month), and severity of the disease. Although our results may be regarded as contrary to the previous studies, the use of FMF-QoL Scale can be an important factor to achieve significant associations on QoL.1,2,9

In previous studies, a higher frequency of anxiety and depression in FMF patients has been reported. ${ }^{3,5,8}$ In accordance with these results, we also detected a higher frequency of anxiety and depression using the subscales of HADS. In correlation analysis, we also showed a positive correlation between the FMF-QoL Scale score and HADS scores. In addition, grouping analysis based on the cut-off level of $\geq 8$ for both anxiety and depression revealed significant correlations. Therefore, the FMF-QoL Scale can also be used as an indirect measure of both anxiety and depression in FMF patients.

As a new QoL scale for FMF patients, we also investigated the correlation of FMF-QoL Scale and the other scales in the same patient group. Our results revealed that FMF-QoL Scale was significantly correlated with SF-36 (physical and mental), HADS (anxiety and depression), HAQ, and FACIT. Therefore, this analysis has also shown the feasibility and reliability of FMF-QoL Scale for FMF patients.

The strengths of our study were the use of a new measurement tool and comparisons with other commonly used scales in a large patient group. For that aspect, this study is one of the most comprehensive studies on QoL in FMF patients. In addition, the inclusion of multiple researchers and centers from the same country also contributed to the strength of the study. On the other hand, the main limitation was the heterogeneity of the patients in relation to the severity of the disease, with the majority of patients ( 95\%) being in the mild and moderate severity groups.

In conclusion, we reported the first study assessing the QoL in FMF patients using the FMF-QoL Scale as a specifically designed patient-reported outcome measurement tool. FMF-QoL Scale was shown to be correlated with other measurement tools. We showed poorer QoL in association with female sex, illiteracy or primary education, monthly low-income (US\$<300), smoking, late-onset FMF ( $>20$ years), a higher number of attacks per month ( $>1 /$ month), and severity of the disease in FMF patients. FMF-QoL Scale was noted as a valid and simple patient-reported outcome instrument and correlated with the SF-36 scale.

\section{Declaration of conflicting interests}

The authors declared no conflicts of interest with respect to the authorship and/or publication of this article.

\section{Funding}

The authors received no financial support for the research and/or authorship of this article.

\section{REFERENCES}

1. Sahin S, Yalcin I, Senel S, Ataseven H, Uslu A, Yildirim $\mathrm{O}$, et al. Assesment life quality of familial Mediterranean fever patients by short form-36 and its relationship with disease parameters. Eur Rev Med Pharmacol Sci 2013;17:958-63. 
2. Alayli G, Durmus D, Ozkaya O, Sen HE, Nalcacioglu H, Bilgici A, et al. Functional capacity, strength, and quality of life in children and youth with familial Mediterranean fever. Pediatr Phys Ther 2014;26:347-52.

3. Kucuksahin O, Omma A, Ozdemirel AE, Tecer $\mathrm{D}$, Ulutas $\mathrm{S}$, Maras $\mathrm{Y}$, et al. Incidence of sleep disturbances in patients with familial Mediterranean fever and the relation of sleep quality with disease activity. Int J Rheum Dis 2018;21:1849-56.

4. Demirkaya E, Acikel C, Hashkes P, Gattorno M, Gul A, Ozdogan H, et al. Development and initial validation of international severity scoring system for familial Mediterranean fever (ISSF). Ann Rheum Dis 2016;75:1051-6.

5. Giese A, Örnek A, Kilic L, Kurucay M, Şendur SN, Lainka E, et al. Anxiety and depression in adult patients with familial Mediterranean fever: a study comparing patients living in Germany and Turkey. Int J Rheum Dis 2017;20:2093-100.

6. Duruoz MT, Unal C, Bingul DK, Ulutatar F. Fatigue in familial Mediterranean fever and its relations with other clinical parameters. Rheumatol Int 2018;38:75-81.

7. Bodur H, Ataman S, Rezvani A, Buğdaycı DS, Cevik $\mathrm{R}$, Birtane M, et al. Quality of life and related variables in patients with ankylosing spondylitis. Qual Life Res 2011:20:543-9.

8. Deger SM, Ozturk MA, Demirag MD, Aslan S, Goker B, Haznedaroglu S, et al. Health-related quality of life and its associations with mood condition in familial Mediterranean fever patients. Rheumatol Int 2011:31:623-8.

9. Giese A, Kurucay M, Kilic L, Örnek A, Şendur SN, Lainka E, et al. Quality of life in adult patients with Familial Mediterranean fever living in Germany or Turkey compared to healthy subjects: a study evaluating the effect of disease severity and country of residence. Rheumatol Int 2013;33:1713-9.

10. Pincus T, Sokka T. Can a Multi-Dimensional Health Assessment Questionnaire (MDHAQ) and Routine Assessment of Patient Index Data (RAPID) scores be informative in patients with all rheumatic diseases? Best Pract Res Clin Rheumatol 2007;21:733-53.

11. Montan I, Löwe B, Cella D, Mehnert A, Hinz A. General Population Norms for the Functional Assessment of Chronic Illness Therapy (FACIT)Fatigue Scale. Value Health 2018;21:1313-21.

12. Unal-Ulutatar C, Duruoz MT. Development and validation of a quality of life scale in Familial Mediterranean Fever (FMFQoL). Mod Rheumatol 2020. [Online ahead of print]
13. Livneh A, Langevitz P, Zemer D, Zaks N, Kees $\mathrm{S}$, Lidar $\mathrm{T}$, et al. Criteria for the diagnosis of familial Mediterranean fever. Arthritis Rheum 1997;40:1879-85.

14. Pras E, Livneh A, Balow JE Jr, Pras E, Kastner DL, Pras $M$, et al. Clinical differences between North African and Iraqi Jews with familial Mediterranean fever. Am J Med Genet 1998;75:216-9.

15. Pinar R. Reliability and construct validity of the SF-36 in Turkish cancer patients. Qual Life Res 2005;14:259-64.

16. Basak F, Hasbahceci M, Guner S, Sisik A, Acar A, Yucel $\mathrm{M}$, et al. Prediction of anxiety and depression in general surgery inpatients: A prospective cohort study of 200 consecutive patients. Int $\mathrm{J}$ Surg 2015;23:18-22.

17. Aydemir Ö. Validity and Reliability of Turkish Version of Hospital Anxiety and Depression Scale. Türk Psikiyatri Dergisi 1997;8:280-7.

18. Maska L, Anderson J, Michaud K. Measures of functional status and quality of life in rheumatoid arthritis: Health Assessment Questionnaire Disability Index (HAQ), Modified Health Assessment Questionnaire (MHAQ), Multidimensional Health Assessment Questionnaire (MDHAQ), Health Assessment Questionnaire II (HAQ-II), Improved Health Assessment Questionnaire (Improved HAQ), and Rheumatoid Arthritis Quality of Life (RAQoL). Arthritis Care Res (Hoboken) 2011;63 Suppl 11:S4-13.

19. Buskila D, Zaks N, Neumann L, Livneh A, Greenberg $\mathrm{S}$, Pras $\mathrm{M}$, et al. Quality of life of patients with familial Mediterranean fever. Clin Exp Rheumatol 1997;15:355-60.

20. Sönmez AÖ, Sönmez HE, Çakan M, Yavuz M, Keskindemirci G, Aktay Ayaz N. The evaluation of anxiety, depression and quality of life scores of children and adolescents with familial Mediterranean fever. Rheumatol Int 2020;40:757-63.

21. Skevington SM, Lotfy M, O'Connell KA; WHOQOL Group. The World Health Organization's WHOQOLBREF quality of life assessment: psychometric properties and results of the international field trial. A report from the WHOQOL group. Qual Life Res 2004;13:299-310.

22. Burckhardt CS, Anderson KL. The Quality of Life Scale (QOLS): reliability, validity, and utilization. Health Qual Life Outcomes 2003;1:60.

23. Varan O, Kucuk H, Babaoglu H, Atas N, Salman RB, Satis $\mathrm{H}$, et al. Effect of interleukin-1 antagonists on the quality of life in familial Mediterranean fever patients. Clin Rheumatol 2019;38:1125-30. 